\title{
Functional Architecture and Specifications for Tolerancing Data and Knowledge Management
}

\author{
Farouk Belkadi, Magali Bosch-Mauchand, Yannick Kibamba, \\ Julien Le Duigou, and Benoit Eynard \\ Université de Technologie de Compiègne \\ Department of Mechanical Systems Engineering \\ CNRS UMR 7337 Roberval \\ firstname. lastname@utc.fr
}

\begin{abstract}
The paper deals with the Computer-Aided Tolerancing and Product Data Management. It is especially focus on data and knowledge management system to support and improve the tolerancing tasks in product development process. The first part of the paper introduces an overview about the recent developments related to tolerancing supports and data management systems. Based on a literature survey and industrial issues, the second part proposes a functional architecture and specifications of the data and knowledge management system addressing the numerous needs clarified by tolerancing experts.
\end{abstract}

Keywords: Tolerancing Process, Product Development Process, Product Data Management, Computer-Aided Tolerancing, Knowledge Reuse.

\section{Introduction}

Nowadays complex products have to meet high performance functions integrating various technologies and numerous components [1]. To cope with this increasing complexity, product development processes involve a large range of data coming from different departments and expertises of the company. These data concern different aspects of the product [2-3] and are generated and used during the whole product lifecycle [4].

Tolerancing expertise is largely impacted by the change process of product data. Indeed, tolerancing process is composed by a sequence of expert tasks that are mainly performed during the detailed design stage [5]. Each one uses the data generated by the previous tasks and creates new data to be used in the following tasks.

Designers used empirical approach based on their backgrounds to define geometric and tolerance specifications. However, the sub-process related to each task is still unknown by other experts (product designer, process engineer, manufacturer ...).

In such a context, one of relevant challenges for industrial companies is how to define an information system that would be a suitable system for data management and sharing. The introduction of Computer-Aided Tolerancing (CAT) tools has offered to designers an efficient support. Three main needs are addressed by CAT systems [6]: 
- Aid for tolerance calculation ;

- Aid for tolerance modeling in the digital mockup;

- Management and traceability of tolerance data among the product lifecycle.

This work addresses the last topic and concerns the definition of the functional architecture of a system for the management of data and knowledge generated by tolerancing process with the aim to improve the performance of the tolerancing process. Section 2 presents a literature survey on tolerancing process and data management. Section 3 describes the proposed functional architecture and specifications of the tolerancing data management system. Before conclusion, the use of such a configuration to integrate tolerancing at the earlier stage of design process is introduced in section 4 .

\section{Literature Survey}

In the last few years, industrial applications of tolerancing have known a significant improvement and during the same time a number of CAT systems have emerged. Each system is used for a special task in a specific stage of design process. In parallel, the data and knowledge management became a subject of several developments in both scientific and industrial fields.

\subsection{Tolerancing Process}

Basically, tolerancing consists in defining consistent dimensional and geometric constraints to ensure the required technical product performance of product.

Salomons et al. [9-10] has divided tolerancing process to four major tasks (Fig. 1): tolerancing specification, tolerancing analysis, tolerancing synthesis and tolerancing verification. Each task has a particular goal.

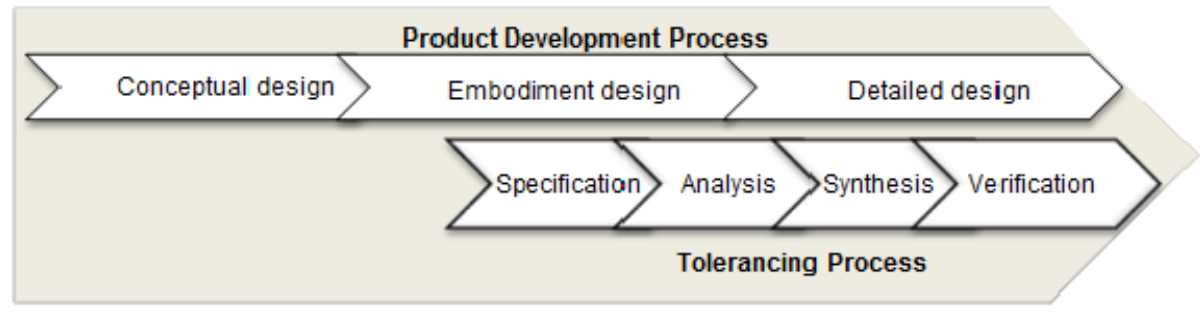

Fig. 1. Tolerancing process $[9-10]$

Tolerancing specification is the task of specifying tolerances, defining the tolerancing types and related tolerancing values. Tolerancing analysis is a method which is used to verify the proper execution of the assembly after tolerances have been specified. It's used as bottom-up approach going from tolerancing value for each isolated part to the value of a functional requirement by calculating the total resultant on the assembly level. On the contrary Tolerancing synthesis is an up-bottom approach 
which consists in determining tolerancing value of each part in order to fulfill a functional requirement. Tolerancing verification defines inspection planning and metrological procedures for functional requirement in order to check the product conformity and to verify assumptions made by designers.

In practice, tolerancing process often starts during detailed design phase when product geometry is totally defined, and therefore any modification of a part dimension becomes a very complex and an expensive task. Furthermore, it is very difficult to keep traceability between functional requirements and functional tolerancing.

There are some existing approaches dealing with tolerancing task in the whole product process [11-12]. For instance, Mathieu et al. [13] has proposed the GEOSPELLING approach which is presented as the basic of a complete and coherent tolerancing process. Dantan et al. [5] has proposed the Integrated Tolerancing Process (ITP), which ensures the continuous transition from functions to functional tolerances. In the same category, Ballu et al. [14] has proposed GASAP approach (Geometric As Soon As Possible) for modeling at earlier parts, assembly and tolerance specifications in a Computer-Aided Design (CAD) system.

To cope with the complexity of tolerancing process, many existing CAT systems developed in the research area, such as the QUICK GPS (Geometric Product Specification) system developed by Anselmetti et al. [6] and aims to automatically generate part tolerance specifications. In general, the Current CAT systems are designed to carry out two main tasks: tolerancing analysis and tolerancing synthesis.

In parallel, it is to note that tolerancing experts manage tolerance with different methodologies according to the business field of each expert and the nature of the problem to be solved. Moreover, during the product development process, several business tools (i.e. CAT systems) are used for different need. The produced data are then dispatched in various supports without any guaranty for their global consistency.

This situation makes it difficult to ensure the management and the traceability between all data used and generated during tolerancing process, and therefore, between functional requirements and tolerances and/or geometric specifications.

\subsection{Data Management Systems}

Regarding the complexity of the tolerancing process, each expert has the need to have more information for the achievement of his activity. For instance, he can be interested to get information about the computing hypothesis and the CAT tools used for obtaining particular results, the followed methodology, the used technical data, etc.

Thus, Tolerance Data Management (TDM) system becomes progressively crucial for the performance of tolerancing task, and therefore for design process. TDM should be fully integrated in a Product Lifecycle Management (PLM) platform to ensure the traceability of tolerancing data through the whole product lifecycle [16].

In the literature, there are some existing approaches dealing with data model for a TDM system. For instance, Feng et al. [17] and Zhao et al. [18] have proposed two data models supporting tolerance data, those models should be improved to take into account of PLM approach. 
The problem of tolerancing data management is a part of more global issue concerning the data management in collaborative product development. In this field, there exist several recent works dealing with models and ontology in order to represent the product knowledge and data. Product modeling techniques in CAD systems currently include parametric design, feature technology, whereas features can contain information regarding geometry and/or semantics [19]. The product model includes not only the geometry and shape [20] but also the higher level of product information (i.e. product \& manufacturing information, geometric dimensioning \& tolerancing).

Product Data Management (PDM) systems are claimed as capable of speeding up the process of distributing engineering information and knowledge, while centralizing management of the overall product development process [21-22]. In the same category, PLM systems is defined as a systematic concept for the integrated management of all product related information and processes through the entire lifecycle, from the initial idea to end-of-life [23-24]. PLM is about integrating various data management tools developed for each stage of the lifecycle of a product in a comprehensive package destined to improve the information and data share between partners, clients and suppliers [24]. The Information Technology (IT) solutions to support PLM approach result from the integration between heterogeneous systems such as Enterprise Resource Planning (ERP), PDM, CAD, Computer-Aided Engineering (CAE), etc. [25].

In another category, because of highlight interactions between design and manufacturing department, Manufacturing Process Management (MPM) systems are rapidly becoming an integral part of modern PLM solutions derived from engineering tools. But they also offer viable and systematic links for integration with ERP platforms [26].

The literature survey about current development of data management systems in the last decades shows an important evolution in terms of functionalities and variety of managed data. Thanks to the advanced interoperability techniques, the recent data management systems offer more capabilities to communicate with different business tool in order to import/export automatically heterogeneous data and update the shared data base during the development process. In parallel, the MPM systems might contribute to the management of tolerancing data since a large part of this data are produced during manufacturing process or are directly linked to some of its resources.

However, despite the large interest given to the tolerancing request, the recent development of data models proposes few concepts for the representation of related knowledge. Indeed, the literature survey and industrial benchmark shows that the manipulated data is not limited to the tolerance values only. The next section proposes a functional architecture for data management system supporting the variety of data and aiming to assist the designer and process engineer in their activity.

\section{Architecture of Tolerancing Data Management System}

The main goal of an integrated system is to facilitate the activity of the designer and process engineer by reducing the dependencies of the tolerancing task with the results of other activities of the development process. In this aim, this section discusses how 
an efficient IT support can contribute to improve the performance of the tolerancing process and how can help starting the tolerancing tasks at the early stages of the product development process, without waiting for the detailed definition of the product.

\subsection{Integrated Tolerancing Process}

In coherence with the literature survey (i.e. GASAP Approach [7]), the proposal of integration of tolerancing activities at the early stages of the design process is based on skeleton and functional features modeling with sufficient details for the definition of functional tolerance of the physical interfaces.

Fig. 2 illustrates the integrated tolerancing process in which, the functional tolerancing is specified at the earlier stages of the design process, especially, when the technical functions are clarified and the principles of solution are identified. The main idea is to define, according to the type of chosen principles of solution, the types of kinematical pairs (KP) and related types of physical interfaces that can implement the defined solution. Then, the designer can specify the functional tolerances of the different interfaces regardless the detailed form of the product that can be obtained progressively by volume modeling based on the skeleton model.

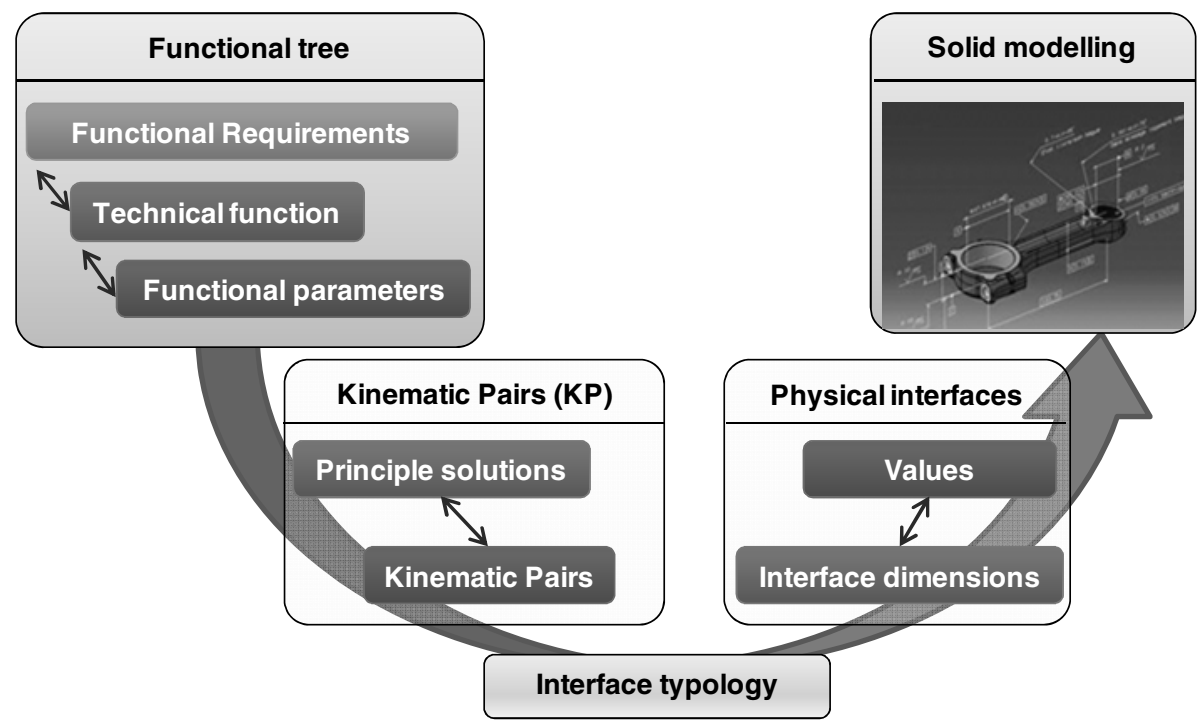

Fig. 2. Integrated tolerancing process

The next sub-section proposes the functional architecture of data management system supporting the integrated tolerancing process. Then, the deployment of some proposed functionalities is developed in the last sub-section. 


\subsection{Functional Architecture of Tolerancing Data Management System}

An analysis of the tolerancing process has been carried out based on literature survey, CAT tools benchmark, tolerancing expert interviews and technical documents created during the tolerancing process. According to this analysis, this research work proposes a functional architecture of the "As to be" system aiming to support tolerancing data management and to aid the expert in charge of tolerances definition by means of different functionalities.

The Table 1 illustrates the proposed architecture that is composed by two main categories of functional modules: Knowledge Management (KM) and Product Lifecycle Management (PLM). The first category includes all functionalities that contribute to preserve and share expert knowledge within a reuse perspective in future projects. The second category concerns the functionalities supporting the collaborative actions and the management and sharing of data during the current tolerancing process.

Table 1. Main functionalities of tolerance data management systems

\begin{tabular}{|c|c|c|}
\hline Category & Functional Module & Functionalities \\
\hline \multirow{7}{*}{$\mathrm{KM}$} & \multirow{4}{*}{ Ontology of Domain } & Library of standards \\
\hline & & Library of methods and practices \\
\hline & & Library of machines' capabilities \\
\hline & & Library of standards Pairs / Interfaces \\
\hline & \multirow{3}{*}{ Project Traceability } & Manufacturing constraints and customer \\
\hline & & Decisions' justification \\
\hline & & Data / Documents versioning \\
\hline \multirow{2}{*}{\multicolumn{2}{|c|}{ Edition }} & Creation / Modification \\
\hline & & Search / Reuse \\
\hline \multirow{10}{*}{ PLM } & \multirow{7}{*}{$\begin{array}{l}\text { Tolerancing Data } \\
\text { Management }\end{array}$} & $\begin{array}{l}\text { Technical Functions / Functional Condi- } \\
\text { tions }\end{array}$ \\
\hline & & Tolerances \\
\hline & & Kinematic Pairs (KP \\
\hline & & Physical interfaces \\
\hline & & Relations TF - FC - Cotes \\
\hline & & $\begin{array}{l}\text { Relations 2D - 3D references / CAD } \\
\text { models }\end{array}$ \\
\hline & & Relations TF - KP - Interfaces \\
\hline & \multirow{3}{*}{ Collaborative Support } & Changes notification \\
\hline & & Validation of tolerance process \\
\hline & & Collaborative viewer for tolerance \\
\hline
\end{tabular}

Globally, four main functional modules are proposed covering both KM and PLM requests. Additional functionalities are also cited for the classical edition needs (Creation / modification; Search / reuse). 
- Ontology of Domain: this module proposes a set of libraries including different generic information that can be exploited on all tolerancing projects in order to reduce time of searching of standards, and current problem solving methods.

- Project Traceability: in several cases, the tolerancing process is beginning by global specifications and completed rigorously in the detailed design stages. Some tolerances are modified at the manufacturing stage in order to consider additional constraints.

- Tolerancing Data Management: This module contains the main functionalities of storage and sharing of data produced and used during the different stages of the tolerancing process.

- Collaborative Support: the tolerancing process is achieved collaboratively by various design team members.

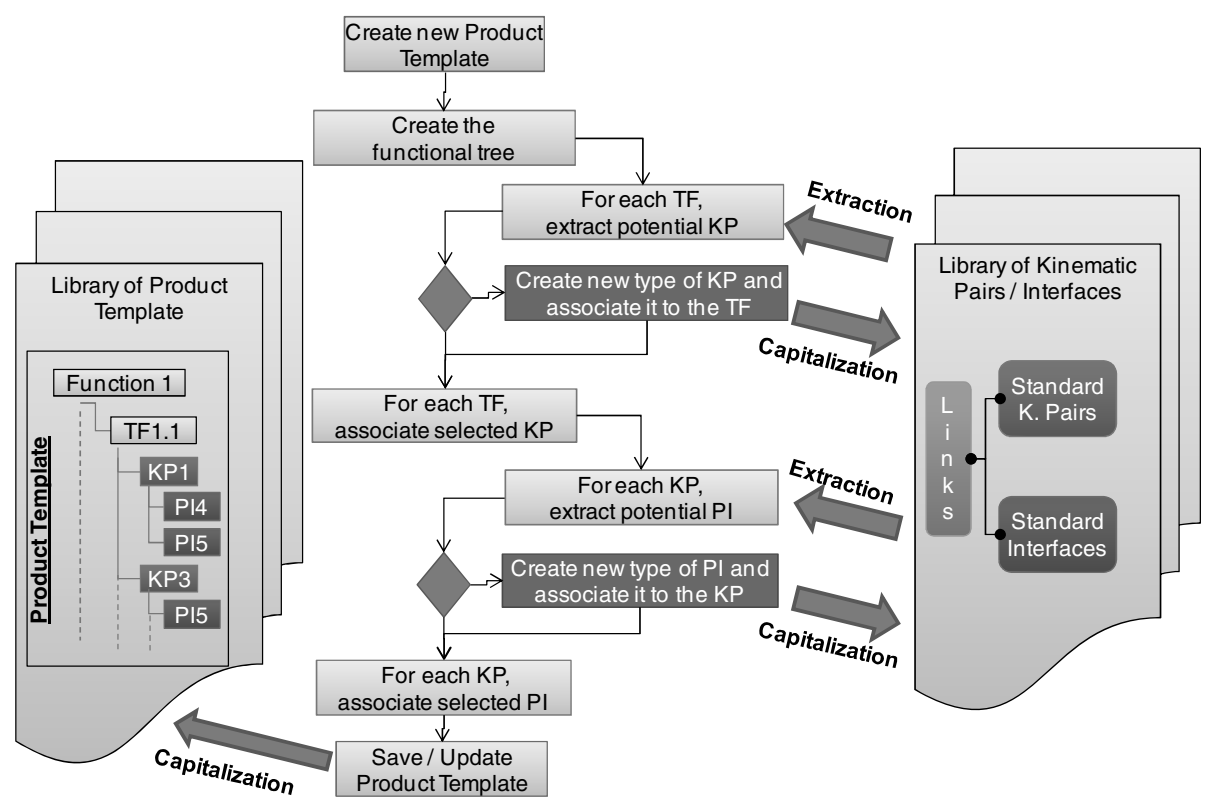

Fig. 3. Building of the product templates

\subsection{Functional Specifications of Tolerancing Data Management System}

The functional specification of the architecture focuses on the ontological and data management principles. Fig. 3 describes the process of product template building that is necessary for the definition of tolerances parameters. In this scenario, the library of kinematic pairs (KP) and related physical interfaces (PI) (KM module) is used to define all possible configurations for each technical function (TF) of the product. A configuration is composed by a set of kinematic pairs able to fulfill the technical function and a set of physical interfaces fulfilling specifications corresponding to each selected kinematic pair. The concept of interface allows linking physical 3D models 
to dimensions and tolerancing parameters. At any moment the user can enrich the content of the library by creating new type of kinematic pair or physical interface and publishing it as a reusable model.

The exploitation of product template for supporting tolerancing task is mainly oriented to support the definition of the good interfaces and aid designer for the definition of the dimensions values of the selected interface according to the type of function and related technical solution (Fig. 4).

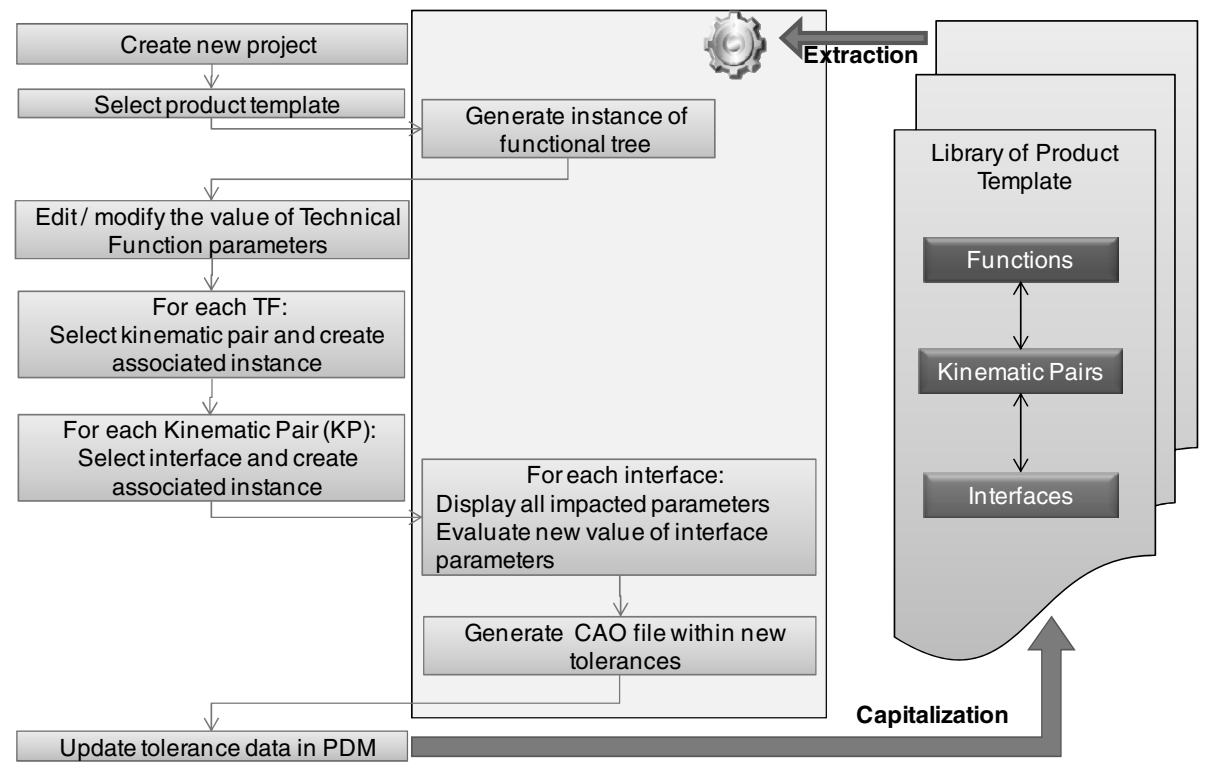

Fig. 4. Template reuse for tolerance definition

In the proposed process, the user can create a new product based on existing product template (extracted from product template library) and introduce the value of the technical functions corresponding to the new project/product. The system proposes respectively the possible kinematic pairs and physical interfaces able to implement the proposed functions and the expert can make a choice relevant with its project.

After the user selection of the complete solution, the system indicates the different interface parameters to be evaluated according to the new values of the technical function. A list of transformation rules should be suggested to the user in order to assist him in the evaluation of new tolerances. Then, the system generates and manages links between the CAD files and the tolerancing data of the product.

\section{Demonstrator Implementation}

This section presents the implementation of the functional architecture in a commercial PLM system focusing on the product template reuse (see section 3). The studied business case concerns the development process of engine piston for car. 
The demonstrator is based on Enovia V6 and Catia V6 from Dassault Systèmes. Enovia handles information related to functional, structural, and parametric aspects of the product. CATIA V6 deals with CAD models including functional 3D tolerances, geometric definition and volume modeling of the product.

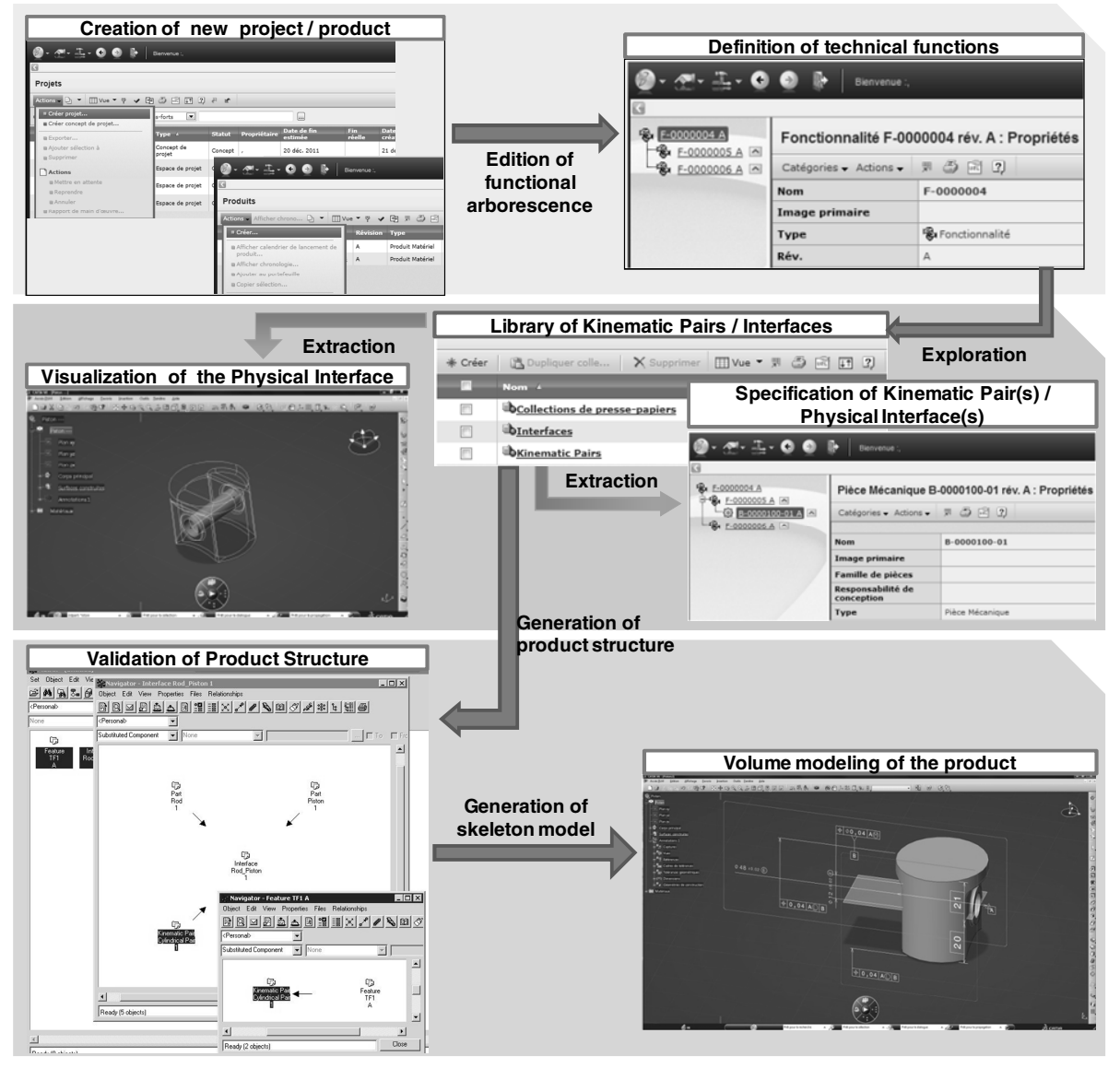

Fig. 5. Demonstrator implementation

For the implementation needs, the Enovia data model has been enriched with specific objects and relations in coherence with the proposed tolerancing process. It concerns kinematic pairs and physical interfaces. Thanks to the collection functionality of Enovia, these objects are typed and organized in a library of reusable elements.

Fig. 5 illustrates the different stages of the deployment of a business case study on the demonstrator. First, the user creates a new project and a new instance of product from existing templates. The technical functions are then defined in the variant configuration module. The third step consists in selecting and specifying the related kinematic pairs and physical interfaces. For this need, the user can visualize at any moment the CAD models of the different interfaces in order to choose the most 
appropriate one. After that, the product structure is generated and validated before the generation of the skeleton model. Finally, the designer completes the volume modeling of the product while taking into account the functional tolerances.

\section{Conclusion}

This paper presented an approach to ensuring a better integration of tolerancing data and related knowledge with PLM system. A functional architecture and specifications of tolerancing data management system have been proposed in order to support this integration at the early stages of the design project.

The main idea is to specify, as soon as possible in the design process, kinematic pairs and physical interfaces to choose design principles and progressively define geometric specifications and tolerances to fulfill functional requirements.

An implementation of the proposed approach on a business case study is performed using Enovia and Catia V6 solutions. This implementation validates the advantages and feasibility of the functional architecture. However, further test and developments are to be carried out for ensuring the robustness and the usability of the IT environment in industrial context.

Acknowledgement. This work is a part of the Quick GPS FUI Project supported by French Government and local public foundings. Quick GPS FUI Project is also endorsed jointly by Systematic and Astech Competitiveness Clusters of Paris Region.

\section{References}

1. Danilovic, M., Browning, T.R.: Managing complex product development projects with design structure matrices and domain mapping matrices. International Journal of Project Management 25(3), 300-314 (2007)

2. Bronsvoort, W.F., Noort, A.: Multiple-view feature modelling for integral product development. Computer-Aided Design 36(10), 929-946 (2004)

3. Xiao, S., Xudong, C., Li, Z., Guanghong, G.: Modeling framework for product lifecycle information. Simulation Modelling Practice and Theory 18(8), 1080-1091 (2010)

4. Stark, J.: Product Lifecycle Management. Springer, London (2011)

5. Dantan, J.Y., Anwer, N., Mathieu, L.: Integrated tolerancing process for conceptual design. CIRP Annals - Manufacturing Technology 52(1), 135-138 (2003)

6. Anselmetti, B., Chavanne, R., Yang, J.X., Anwer, N., Quick, G.P.S.: A new CAT system for single part tolerancing. Computer-Aided Design 42(9), 768-780 (2010)

7. Toulorge, H., Riviere, A., Bellacicco, A., Sellakh, R.: Towards a Digital Functional Assistance Process for Tolerancing. Journal of Computing and Information Science in Engineering 3(1), 39-44 (2003)

8. Sudarsan, R., Fenves, S.J., Sriram, R.D., Wang, F.: A product information modeling framework for product lifecycle management. Computer-Aided Design 37(13), 1399-1411 (2005) 
9. Salomons, O.W., Haalboom, F.J., Jonge Poerink, H.J., Van Slooten, F., Van Houten, F.J.A.M., Kals, H.J.J.: A computer aided tolerancing tool I: Tolerancing specification. Computers in Industry 31(2), 161-174 (1996)

10. Salomons, O.W., Haalboom, F.J., Jonge Poerink, H.J., Van Slooten, F., Van Houten, F.J.A.M., Kals, H.J.J.: A computer aided tolerancing tool II: Tolerancing analysis. Computers in Industry 31(2), 175-186 (1996)

11. Tichkiewitch, S., Brissaud, D.: Diverse aspects of tolerancing on an integrated design context. CIRP Annals - Manufacturing Technology 48(1), 107-110 (1999)

12. Khanafer, M., Desrochers, A., Laperrière, L.: Tolerancing assistance methodology in a product life cycle perspective, Anaheim, CA (2007)

13. Mathieu, L., Ballu, A.: GEOSPELLING/ A common language for specification and verification to express method uncertainty. In: 8th CIRP Seminar on Computer Aided Tolerancing (2005)

14. Ballu, A., Falgarone, H., Chevassus, N., Mathieu, L.: A new Design Method based on Functions and Tolerance Specifications for Product Modelling. CIRP Annals - Manufacturing Technology 55(1), 139-142 (2006)

15. Anselmetti, A.: Generation of functional tolerancing based on positioning features. Computer-Aided Design 38(8), 902-919 (2006)

16. Rhahli, Y., Bosch, M., Anselmetti, B., Eynard, B.: A survey on tolerancing task integration in PLM. In: 9th International Conference on Integrated design and Manufacturing in Mechanical Engineering, IDMME 2010, Bordeaux, France, October 20-22 (2010)

17. Feng, S.C., Yang, Y.: A dimension and tolerance data model for concurrent design and systems integration. Journal of Manufacturing Systems 14(6), 406-426 (1995)

18. Zhao, X., Pasupathy, T.M.K., Wilhelm, R.G.: Modeling and representation of geometric tolerances information in integrated measurement processes. Computers in Industry 57(4), 319-330 (2006)

19. Krause, F.L., Weiss, Z., Hermann, C., Frad, A., Ragan, Z., Karwasz, A.: New approach for the end of life oriented product conceptual design. In: 2nd International Conference on Virtual Design and Automation, Poznań, Poland, November 28-29 (2005)

20. Liu, W., Zeng, Y., Maletz, M., Brisson, D.: Product Lifecycle Management: a review. In: ASME International Design Engineering Technical Conferences \& Computers and Information in Engineering Conference, San Diego, USA, August 30-September 2 (2009)

21. Liu, D.T., Xu, X.W.: A review of web-based product data management systems. Computers in Industry 44(3), 251-262 (2001)

22. Eynard, B., Gallet, T., Nowak, P., Roucoules, L.: UML based specifications of PDM product structure and workflow. Computers in Industry 55(3), 301-316 (2004)

23. Terzi, S., Bouras, A., Dutta, D., Garetti, M., Kiritsis, D.: Product lifecycle management from its history to its new role. International Journal of Product Lifecycle Management 4(4), 360-389 (2010)

24. Saaksvuori, A., Immonen, A.: Product Lifecycle Management. Springer, Berlin (2006)

25. Schuh, G., Rozenfeld, H., Assmus, D., Zancul, E.: Process oriented framework to support PLM implementation. Computers in Industry 59(2-3), 210-218 (2008)

26. Galeta, T., Kljajin, M., Karakasic, M.: Supporting product development process through the ERP system. Tehnicki Vjesnik 15(2), 25-34 (2008) 